\title{
Familiality and SNP heritability of age at onset and episodicity in major depressive disorder
}

\author{
P. Ferentinos ${ }^{1,2 *}$, A. Koukounari ${ }^{3}$, R. Power ${ }^{1}$, M. Rivera ${ }^{1,4}$, R. Uher ${ }^{1,5}$, N. Craddock ${ }^{6}$, M. J. Owen ${ }^{6}$, \\ A. Korszun ${ }^{7}$, L. Jones ${ }^{8}$, I. Jones ${ }^{6}$, M. Gill ${ }^{9}$, J. P. Rice ${ }^{10}$, M. Ising ${ }^{11}$, W. Maier ${ }^{12}$, O. Mors ${ }^{13}$, \\ M. Rietschel ${ }^{14}$, M. Preisig ${ }^{15}$, E. B. Binder ${ }^{11}$, K. J. Aitchison ${ }^{16}$, J. Mendlewicz ${ }^{17}$, D. Souery ${ }^{18}$, \\ J. Hauser $^{19}$, N. Henigsberg ${ }^{20}$, G. Breen ${ }^{1,21}$, I. W. Craig ${ }^{1}$, A. E. Farmer ${ }^{1}$, B. Müller-Myhsok ${ }^{11}$, \\ P. McGuffin ${ }^{1}$ and C. M. Lewis ${ }^{1,22}$ \\ ${ }^{1}$ MRC Social Genetic and Developmental Psychiatry Centre, Institute of Psychiatry, Psychology and Neuroscience, King's College London, \\ London, UK; ${ }^{2}$ 2nd Department of Psychiatry, Attikon General Hospital, University of Athens, Athens, Greece; ${ }^{3}$ Department of Biostatistics, \\ Institute of Psychiatry, Psychology and Neuroscience, King's College London, London, UK; ${ }^{4}$ Centro de Investigación Biomédica en Red de Salud \\ Mental CIBERSAM, University of Granada, Spain; ${ }^{5}$ Dalhousie University Department of Psychiatry, Halifax, Nova Scotia, Canada; ${ }^{6}$ MRC \\ Centre for Neuropsychiatric Genetics and Genomics, Neuroscience and Mental Health Research Institute, Cardiff University, Cardiff, UK; \\ ${ }^{7}$ Barts and The London Medical School, Queen Mary University of London, London, UK; ${ }^{8}$ Department of Psychiatry, University of \\ Birmingham, Birmingham, UK; ${ }^{9}$ Department of Psychiatry, Trinity Centre for Health Science, Dublin, Ireland; ${ }^{10}$ Department of Psychiatry, \\ Washington University, St. Louis, Missouri, USA; ${ }^{11}$ Max Planck Institute of Psychiatry, Munich, Germany; ${ }^{12}$ Department of Psychiatry, \\ University of Bonn E German Center of Neurodegenerative Diseases (DZNE), Bonn, Germany; ${ }^{13}$ Centre for Psychiatric Research, Aarhus \\ University Hospital, Risskov, Denmark; ${ }^{14}$ Division of Genetic Epidemiology in Psychiatry, Central Institute of Mental Health, Mannheim, Germany; \\ ${ }^{15}$ University Hospital Center and University of Lausanne, Lausanne, Switzerland; ${ }^{16}$ Departments of Psychiatry and Medical Genetics, \\ University of Alberta, Edmonton, Alberta, Canada; ${ }^{17}$ Department of Psychiatry, Free University of Brussels, Brussels, Belgium; \\ ${ }^{18}$ Centre Européen de Psychologie Médicale PSY-PLURIEL, Bruxelles, Belgium; ${ }^{19}$ Department of Genetics in Psychiatry, Poznan University of \\ Medical Sciences, Poznan, Poland; ${ }^{20}$ Department of Psychiatry, University of Zagreb, Zagreb, Croatia; ${ }^{21}$ NIHR Biomedical Research Centre for \\ Mental Health, South London and Maudsley NHS Foundation Trust and Institute of Psychiatry, Psychology and Neuroscience, King's College \\ London, London, UK; ${ }^{22}$ Division of Genetics and Molecular Medicine, King's College London, London, UK;
}

Background. Strategies to dissect phenotypic and genetic heterogeneity of major depressive disorder (MDD) have mainly relied on subphenotypes, such as age at onset (AAO) and recurrence/episodicity. Yet, evidence on whether these subphenotypes are familial or heritable is scarce. The aims of this study are to investigate the familiality of $\mathrm{AAO}$ and episode frequency in MDD and to assess the proportion of their variance explained by common single nucleotide polymorphisms (SNP heritability).

Method. For investigating familiality, we used 691 families with 2-5 full siblings with recurrent MDD from the DeNt study. We fitted (square root) AAO and episode count in a linear and a negative binomial mixed model, respectively, with family as random effect and adjusting for sex, age and center. The strength of familiality was assessed with intraclass correlation coefficients (ICC). For estimating SNP heritabilities, we used 3468 unrelated MDD cases from the RADIANT and GSK Munich studies. After similarly adjusting for covariates, derived residuals were used with the GREML method in GCTA (genome-wide complex trait analysis) software.

Results. Significant familial clustering was found for both AAO $(\mathrm{ICC}=0.28)$ and episodicity $(\mathrm{ICC}=0.07)$. We calculated from respective ICC estimates the maximal additive heritability of AAO (0.56) and episodicity (0.15). SNP heritability of AAO was 0.17 ( $p=0.04)$; analysis was underpowered for calculating SNP heritability of episodicity.

Conclusions. AAO and episodicity aggregate in families to a moderate and small degree, respectively. AAO is under stronger additive genetic control than episodicity. Larger samples are needed to calculate the SNP heritability of episodicity. The described statistical framework could be useful in future analyses.

Received 25 October 2014; Revised 11 January 2015; Accepted 22 January 2015; First published online 20 February 2015

Key words: Age at onset, episodicity, familiality, GCTA, heritability, major depression.

\footnotetext{
* Address for correspondence: Dr P. Ferentinos, MRC Social Genetic and Developmental Psychiatry Centre, Institute of Psychiatry, Psychology and Neuroscience, King's College London, 16 De Crespigny Park, London SE5 8AF, UK and 2nd Department of Psychiatry, Attikon General Hospital, University of Athens, Athens, Greece.

(Email: panagiotis.ferentinos@kcl.ac.uk; pferentinos@med.uoa.gr)
}

\section{Introduction}

Despite extensive research in the field, the genetic architecture of major depressive disorder (MDD) remains highly elusive. Eight genome-wide association studies (GWAS) of MDD have been published (Sullivan et al. 2009; Lewis et al. 2010; Muglia et al. 2010; Rietschel et al. 2010; Kohli et al. 2011; Shi et al.

This is an Open Access article, distributed under the terms of the Creative Commons Attribution licence (http://creativecommons.org/licenses/by/3.0/), which permits unrestricted re-use, distribution, and reproduction in any medium, provided the original work is properly cited. 
2011; Shyn et al. 2011; Wray et al. 2012), with only one locus of genome-wide significance (Kohli et al. 2011). A recently published mega-analysis of GWAS studies in MDD by the Psychiatric Genomics Consortium (PGC) failed to identify any genome-wide significant findings (PGC, 2013). Phenotypic and genetic heterogeneity have been pinpointed as partly responsible for these as yet unfruitful investigations.

Promising strategies to dissect MDD heterogeneity have mainly relied on subphenotypes such as age at onset (AAO) and recurrence/episodicity. Many researchers have used samples enriched in recurrent and early-onset forms (Shi et al. 2011; PGC, 2013) as these clinical subtypes are most consistently associated with higher familial aggregation and heritability of MDD (Sullivan et al. 2000). Other studies have directly focused on genetic correlates of the specific subphenotypes (AAO, episode frequency), analyzed as continuous traits (Power et al. 2012; Ferentinos et al. 2014). Yet, evidence on whether these subphenotypes are per se familial or heritable is scarce in MDD. Small or nil heritabilities for AAO and episode count, respectively, were reported in a small sample of 176 female twin pairs with MDD (Kendler et al. 1992).

Classical methods to estimate the narrow-sense heritability of quantitative traits, i.e. the percentage of phenotypic variance explained by additive genetic effects $\left(V_{\mathrm{A}} / V_{\mathrm{P}}\right)$, rely on observed familial aggregation or phenotypic resemblance among relatives (parents-offspring, full-siblings, half-siblings, twins), usually on the basis of non-verifiable assumptions (random mating, absence of significant dominance, epistatic, and shared environmental effects or gene-environment correlation and interaction) (Visscher et al. 2008; Tenesa \& Haley, 2013). The recently developed genome-wide complex trait analysis (GCTA) software (Yang et al. 2011) employs observed genetic covariance calculated from GWAS data in restricted maximum-likelihood linear mixed models (GREML) for unrelated subjects to estimate the percentage of phenotypic variance explained by common single nucleotide polymprphisms (i.e. the SNP heritability of a trait), without having to rely on those assumptions; SNP heritability estimates provide a lower bound on the total narrow-sense heritability of a phenotype (Zaitlen \& Kraft, 2012).

Since subtyping is increasingly used in MDD genetic research, more evidence on the familial aggregation and heritability of subphenotypes, such as AAO and episodicity (which together reflect the disorder's temporal profile) would be valuable. The aims of this study are, therefore: first, to investigate the familiality of AAO and episode frequency of MDD (studied as quantitative/continuous phenotypes) and thereby infer estimates of their narrow-sense heritability (i.e. the proportion of the variance of $\mathrm{AAO}$ and episode frequency in MDD cases explained by additive genetic effects); second, to assess the SNP heritability of these subphenotypes in unrelated subjects with MDD.

\section{Subjects and method}

\section{Samples}

For the investigation of familial effects, we used subjects from the DeNt (Depression Network) affected siblings study (Farmer et al. 2004; McGuffin et al. 2005; Breen et al. 2011), which comprises cases of recurrent depression fulfilling DSM-IV and/or ICD-10 criteria of at least moderate severity ascertained from three UK clinical sites (London, Cardiff, Birmingham), four other European sites (Aarhus, Bonn, Dublin, Lausanne) and a site in St Louis, USA. One familial cluster of affected full siblings was identified in each family; in extended families, we used only the sibship including the proband or the sibship with most complete data on AAO and episode frequency. A total of 1498 subjects from 691 families with 2-5 affected full siblings were extracted for statistical analysis (Table 1).

For the assessment of the SNP heritability of AAO, we used 3468 genotyped, unrelated MDD cases with complete data on age and AAO; 2695 cases were obtained from the RADIANT study, i.e. from the Depression Case-Control (DeCC) $(N=1023)$, DeNt $(N=843)$, GSK Case-Control $(N=140)$ and GENDEP $(N=689)$ studies, while 773 cases were obtained from the GSK Munich study. The DeCC study includes cases of recurrent depression of at least moderate severity ascertained from three UK sites (London, Cardiff, Birmingham) (Cohen-Woods et al. 2009). One proband from each DeNt family was genotyped and also included in the RADIANT study. The GSK Case-Control study includes cases of recurrent depression collected in Bonn and Lausanne in collaboration with GSK, using exactly the same protocol as the DeNt study. Cases from GENDEP (Uher et al. 2009), a pharmacogenetic study, were ascertained from various sites across Europe (London, Brussels, Mannheim, Bonn, Brescia, Aarhus, Ljubljana, Poznan, Zagreb); while recurrence was not a requirement, $59.5 \%$ of GENDEP cases suffered from recurrent MDD. The GSK Munich sample includes cases of recurrent depression of at least moderate severity recruited for a case-control study in the Munich area in collaboration with GSK (Tozzi et al. 2008; Muglia et al. 2010). To calculate the SNP heritability of episodicity, we extracted a subset of 2368 cases with recurrent MDD from the total sample with complete data on episode count (as well as on age and AAO), i.e. 994 DeCC, 833 DeNt, 139 GSK Case-Control and 402 GSK Munich cases.

In the RADIANT studies, only adults of European ancestry were recruited. Subjects were excluded if 
Table 1. Composition of the DeNt affected full-siblings sample

\begin{tabular}{lcc}
\hline $\begin{array}{l}\text { Number of affected } \\
\text { siblings per family }\end{array}$ & $\begin{array}{l}\text { Number of } \\
\text { families }\end{array}$ & $\begin{array}{l}\text { Number of affected } \\
\text { individuals (\%) }\end{array}$ \\
\hline 2 & 600 & $1200(80.1)$ \\
3 & 73 & $219(14.6)$ \\
4 & 11 & $44(2.9)$ \\
5 & 7 & $35(2.3)$ \\
Total & 691 & $1498(100.0)$ \\
\hline
\end{tabular}

there was a history or family history (in first- or second-degree relatives) of schizophrenia, schizoaffective disorder or bipolar disorder, if they had experienced mood-incongruent psychotic symptoms, or if mood symptoms were solely related to alcohol or substance misuse or only secondary to medical illness or medication. Inclusion/exclusion criteria in the GSK Munich study were identical to those used in the DeCC and DeNT studies, except that subjects with a family history of bipolar disorder were not excluded. Therefore, we removed the latter from the analyses.

All subjects were interviewed with the Schedules for Clinical Assessment in Neuropsychiatry (SCAN; Wing et al. 1990), focusing on their worst and second-worst episodes of depression. AAO was recorded in SCAN items 1.016, 1.046-1.048 and 6.025; episode count was recorded in SCAN items 1.053 and 6.030. Family history of MDD in first-degree relatives was also extracted from SCAN item 1.045. All study participants provided written informed consent and approval was obtained from local ethics committees.

Whole-genome genotyping in the RADIANT sample was performed using the Illumina HumanHap610Quad BeadChip. Genotyping in the GSK Munich sample was performed on the Illumina Human-Hap550K platform. Stringent quality control procedures were applied to individual and SNP data in both studies leaving a total of 471581 and 511503 SNPs, respectively, finally eligible for analysis (for full details see Lewis et al. 2010; Muglia et al. 2010). The two samples were then merged using PLINK v. 1.07 (Purcell et al. 2007) and taking into account flipped strands issues; the merged sample, including 427946 SNPs shared by the original samples, was finally used with GCTA software.

\section{Ethical standards}

The authors assert that all procedures contributing to this work comply with the ethical standards of the relevant national and institutional committees on human experimentation and with the Helsinki Declaration of 1975, as revised in 2008.

\section{Method}

\section{Statistical modeling}

Descriptive statistics were used to investigate the distributions of all variables in the DeNt families and genotyped case sets. AAO was analyzed as a continuous variable in linear mixed models; however, as it had a positively skewed distribution, it was first transformed to square root AAO (sqrtAAO) to approach normality. Lifetime number of depressive episodes was a count variable; therefore, we considered Poisson and negative binomial (NB) models as most suitable in subsequent analyses. Episode frequency was defined as the rate of the lifetime number of depressive episodes over the total duration of MDD (=age - age at onset). As its distribution was also highly skewed, a natural logarithm transformation (lnepisfreq) was used for this dependent variable in fitted linear models.

\section{Investigation of familial effects}

To investigate the familiality of AAO in the DeNt siblings sample, we initially fitted a three-level linear mixed model (LMM) with sqrtAAO as the dependent variable, sex as fixed effect covariate and center and family as random effects (subjects nested within families; families nested within centers). Familiality of sqrtAAO was documented if the variance of the random effect of family was significantly greater than zero. The strength of the familial effect was measured by calculating the family-level residual intraclass correlation coefficient (ICC) and its confidence interval (CI) (Wynants et al. 2013); the residual ICC represents the proportion of the residual variance of sqrtAAO (after taking into account the effect of fixed covariates - in this case sex) accounted for by family membership. As it has been suggested that AAO can be considered a censored variable and siblings correlated in chronological age will also tend to be correlated in AAO (Schulze et al. 2006), we also fitted a model additionally including age as a fixed effects covariate and calculated the significance of the family random effect as well as the ICC. Analyses were implemented with the Stata v. 13 (StataCorp, 2013) mixed command.

To investigate the familiality of episodicity in the DeNt siblings sample, we employed two methods. In the first method, we fitted a two-level NB generalized linear mixed model (GLMM) with episode count as the dependent variable, sex, age and center as fixed effects covariates, (ln)MDD duration as offset variable (this reflects the time over which the count response is generated) and family as random effect (subjects nested within families; families nested within centers). Analysis was performed with the Stata v. 13 menbreg command, with adaptive Gauss-Hermite quadrature as integration 
method (seven integrations points) (Bolker et al. 2009). Familiality of episodicity was similarly assessed by testing whether the variance of the family random effect was significantly greater than zero. The family-level ICC for episodicity and its CI, i.e. the proportion of the variance of episode frequency explained by family membership after taking into account the effect of center, were finally calculated in a 'reduced' version of our model, i.e. one without any subject-level covariates (sex, age), on the basis of recent work formulating an ICC in GLMMs for overdispersed count data (see Supplementary Method) (Carrasco, 2010). We also used a second method to investigate the familiality of episodicity as it was previously used to investigate the familial variation of episode frequency in bipolar disorder (Fisfalen et al. 2005); we fitted a three-level LMM with lnepisfreq as the dependent variable, sex and age as fixed effects covariates, and center and family as random effects (subjects nested within families; families nested within centers). Familiality of lnepisfreq was similarly investigated. A family-level residual ICC and its CI were finally calculated.

\section{Inference of narrow-sense heritability from familiality}

Observed phenotypic covariance between relatives (familiality) can be partitioned to causal genetic and environmental covariance components; for full siblings, phenotypic covariance is the sum of half their additive genetic variance plus a quarter of the dominance variance plus the shared environment variance (the contribution of epistatic interactions is ignored) $\left(\mathrm{COV}_{\mathrm{FS}}=1 / 2 V_{\mathrm{A}}+1 / 4 V_{\mathrm{D}}+V_{\mathrm{C}}\right)$ and their phenotypic correlation is the ratio of their phenotypic covariance by the phenotypic variance $\left(\mathrm{ICC}=\mathrm{COV}_{\mathrm{FS}} / V_{\mathrm{P}}\right)$ (Falconer \& Mackay, 1996; Tenesa \& Haley, 2013). Therefore, twice the full-siblings correlation $(2 \times$ ICC) is a good estimate of narrow-sense heritability $\left(V_{\mathrm{A}} / V_{\mathrm{P}}\right)$ only when dominance and shared environment contributions are assumed negligible and can hence provide an upper bound estimate of heritability ('maximal heritability').

\section{Assessment of SNP heritabilities}

To investigate the SNP heritability of AAO in genotyped cases (merged RADIANT and GSK Munich samples), we first fitted a LMM with sqrtAAO as the dependent variable, sex and study as fixed-effects covariates and center as random effect; we then saved the residuals. Analysis was performed with the Stata v. 13 mixed command. The model residuals were then used to calculate the SNP heritability of AAO with the GREML method in GCTA software, using 10 principal components as covariates, a genetic relationship matrix (GRM) cut-off of 0.025 and a minor allele frequency (MAF) cut-off of 0.01 .
To investigate the SNP heritability of episodicity in genotyped cases, we employed two methods to obtain an adjusted episodicity variable. In the first method, we fitted a NB GLMM (Stata v. 13 menbreg command) with episode count as the dependent variable, sex, age and study as fixed-effects covariates, center as random effect, (ln)MDD duration as offset variable, and saved episode frequency deviance residuals. As their distribution was slightly skewed, we rank-normalized them using Blom's formula (Blom, 1958). The ranknormalized adjusted episodicity residuals were then used to calculate the SNP heritability of episodicity with GCTA software, using the same specifications as above. In the second method, we fitted a LMM with lnepisfreq as the dependent variable, sex, age and study as fixed-effects covariates, and center as random effect. We then saved the residuals, rank-normalized them using Blom's formula, and finally used them with GCTA software as previously described.

We finally estimated the SNP heritabilities of AAO and episodicity that could be detected with a power of $80 \%$ (Visscher et al. 2014).

\section{Results}

Demographic and clinical characteristics of DeNt siblings and genotyped cases (RADIANT and GSK Munich samples and their merge) are shown in Table 2 and Supplementary Table S1. Frequency distributions (histograms) of age, AAO, episode count and episode frequency in genotyped cases (Fig. 1, Supplementary Fig. S2) and in DeNT siblings (Supplementary Fig. S1) were plotted.

\section{Familiality of AAO and episode frequency}

In the LMM for sqrtAAO in the DeNt sample $(N=$ 1403), the variance of the family random effect was significantly greater than zero; the family-level residual ICC was 0.278 (95\% CI 0.185-0.395) (Table 3, Supplementary Table S2a). When we additionally included age as a fixed-effects covariate in our model, we obtained a lower but still significant family-level residual ICC of 0.229 (95\% CI 0.140-0.354) (Table 3, Supplementary Table S2b).

Our NB GLMM for episodicity in the DeNt sample $(N=878)$ fitted the observed data better than a corresponding Poisson model (Supplementary Table S3). The variance of the family random effect was significantly greater than zero in both the 'full' and the 'reduced' model (Table 3, Supplementary Table S3). The family-level ICC for episodicity and its CI were calculated on our 'reduced' model (online Supplementary Table S3b). We recorded the overdispersion (alpha) parameter and the variance of the 
Table 2. Demographic and clinical characteristics of DeNT siblings and genotyped cases (merged RADIANT and GSK Munich samples)

\begin{tabular}{lll}
\hline & DeNt siblings $(N=1498)$ & Genotyped cases $(N=3468)$ \\
\hline Sex (females) & $73.4 \%(N=1498)$ & $69.8 \%(N=3468)$ \\
Age (yr) & $44.8 \pm 11.9(18-80)(N=1498)$ & $46.2 \pm 12.7(18-87)(N=3468)$ \\
Age at onset $(y r)$ & $22.8 \pm 11.2(0-74)(N=1403)$ & $27.6 \pm 13.2(1-78)(N=3468)$ \\
MDD duration $(y r)$ & $22.1 \pm 12.9(0-68)(N=1403)$ & $18.7 \pm 13.7(0-71)(N=3468)$ \\
Episode count & $5.5 \pm 8.2(2-100)(N=898)$ & $4.0 \pm 4.7(2-50)(N=2368)$ \\
Episode frequency (episodes/yr) & $0.32 \pm 0.36(0.03-3.0)(N=878)$ & $0.29 \pm 0.35(0.03-3.0)(N=2368)$ \\
\hline
\end{tabular}

Quantitative data are presented as mean \pm S.D. (range).
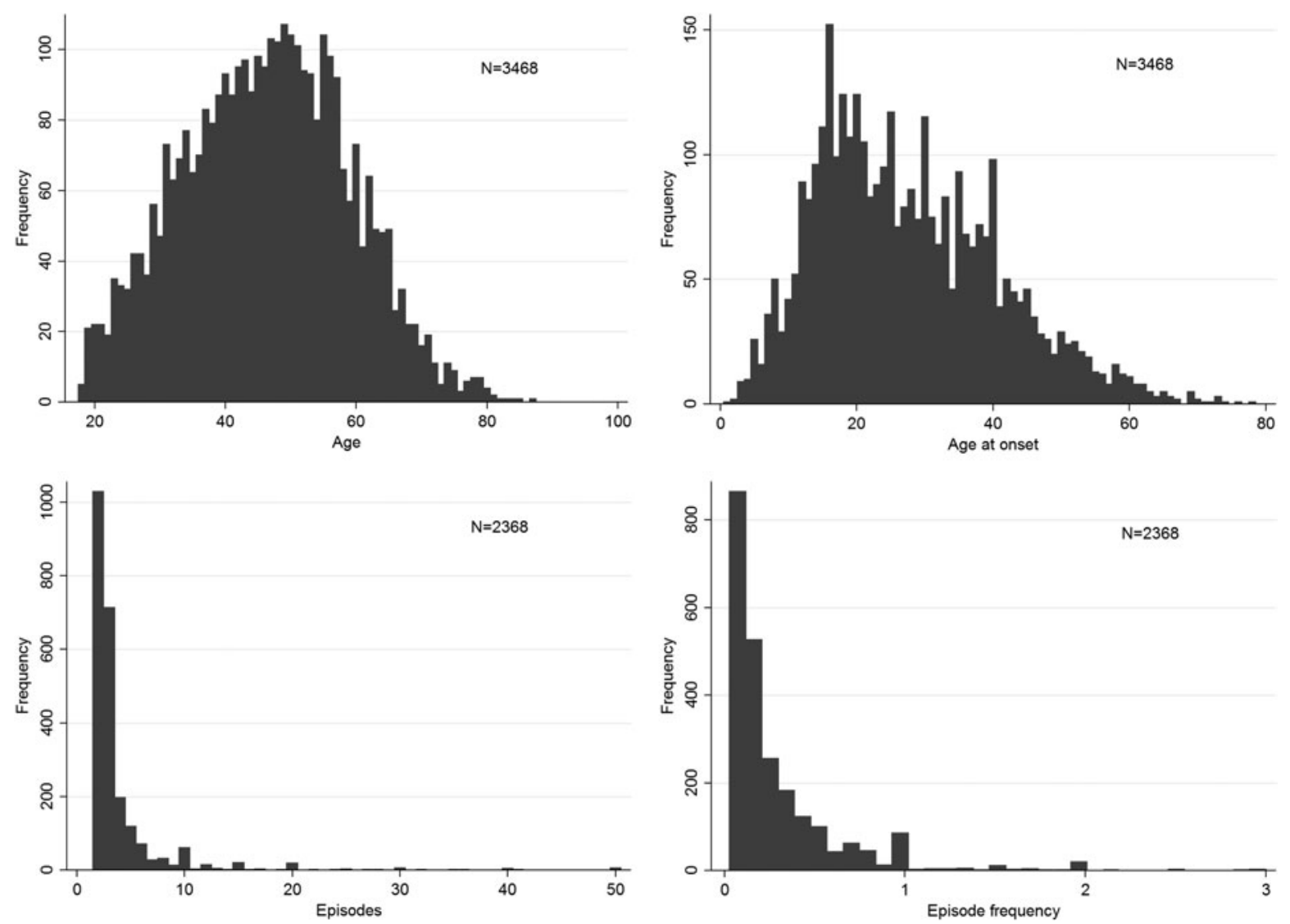

Fig. 1. Frequency distributions (histograms) of $(a)$ age, $(b)$ age at onset, $(c)$ episode count and $(d)$ episode frequency in genotyped cases (merged RADIANT and GSK Munich samples).

family random effect; we also calculated center variance and episode frequency marginal expectation over families. The family-level ICC for episodicity was finally estimated with the Stata v. 13 nlcom command using all aforementioned parameter estimates on the basis of Carrasco's formulae (full details in Supplementary Method $) ; \mathrm{ICC}=0.074$, s.E. $=0.012(95 \%$ CI 0.051-0.096).

In the LMM for lnepisfreq in the DeNt sample, the variance of the family random effect was significantly greater than zero; the family-level residual ICC was
0.167 (95\% CI 0.089-0.292) (Table 3, Supplementary Table S4).

\section{Calculation of 'maximal heritability' from familiality (ICC estimates)}

Assuming dominance and shared environment variance components are negligible, narrow-sense heritability reaches its upper limit ('maximal heritability'), which is twice the ICC estimate. Maximal heritability estimates obtained are 0.46 and 0.56 for AAO 
Table 3. Familiality of age at onset (AAO) and episodicity (two methods) in the DeNt affected full-siblings sample

\begin{tabular}{|c|c|c|c|c|c|c|}
\hline Dependent variable & Fixed effects & Random effects & Log-likelihood & $\begin{array}{l}\text { Likelihood ratio test } \\
\text { (one-tailed } \chi^{2}, \mathrm{df}=1 \text { ) }\end{array}$ & $p$ value & ICC \\
\hline \multirow[t]{2}{*}{$\mathrm{AAO}^{\mathrm{a}}$} & Sex & $\begin{array}{l}\text { Center, family } \\
\text { Center }\end{array}$ & $\begin{array}{l}-2108.30 \\
-2122.96\end{array}$ & 29.32 & $<0.001$ & $0.278^{\mathrm{d}}$ \\
\hline & Sex, age & $\begin{array}{l}\text { Center, family } \\
\text { Center }\end{array}$ & $\begin{array}{l}-2040.70 \\
-2048.75\end{array}$ & 16.11 & $<0.001$ & $0.229^{\mathrm{d}}$ \\
\hline Episodicity (NB GLMM) ${ }^{\mathrm{b}}$ & Sex, age, center & $\begin{array}{l}\text { Family } \\
\text { None }\end{array}$ & $\begin{array}{l}-2310.95 \\
-2351.18\end{array}$ & 80.47 & $<0.001$ & $0.074^{\mathrm{e}}$ \\
\hline Episodicity $(\mathrm{LMM})^{\mathrm{c}}$ & Sex, age & $\begin{array}{l}\text { Center, family } \\
\text { Center }\end{array}$ & $\begin{array}{l}-1043.51 \\
-1047.29\end{array}$ & 7.56 & 0.003 & $0.167^{\mathrm{d}}$ \\
\hline
\end{tabular}

\footnotetext{
${ }^{\text {a }}$ Linear mixed model with sqrtAAO as dependent variable.

${ }^{\mathrm{b}}$ Negative binomial generalized linear mixed model (NB GLMM) with episode count as dependent variable and (ln)MDD duration as offset variable.

${ }^{\mathrm{c}}$ Linear mixed model (LMM) with $\ln$ (episode frequency) as dependent variable.

${ }^{\mathrm{d}}$ Residual intraclass correlation coefficient (ICC) calculated in the 'full' model with all covariates.

e ICC calculated in a model without subject-level covariates ('reduced' model, i.e. without sex and age) (Carrasco, 2010).
}

(depending on whether age was included as covariate in the model or not, respectively) and 0.15 and 0.33 for episodicity (depending on the method of calculation used, NB GLMM or LMM, respectively) (Table 4).

\section{SNP heritability of AAO and episode frequency}

In the LMM for sqrtAAO $(N=3468)$, we saved the residuals and then used them with the GREML procedure in GCTA software (Supplementary Table S5). The SNP heritability of sqrtAAO was calculated at 0.175 (s.E. $=$ $0.104, p=0.042$ ).

In the NB GLMM of episodicity $(N=2368)$, we saved episode frequency deviance residuals, rank-normalized them and then used them with the GREML procedure in GCTA software (Supplementary Table S6). The SNP heritability of episodicity was estimated at 0.092 (S.E. $=$ $0.143, p=0.260)$.

In the LMM of lnepisfreq, we saved lnepisfreq residuals, rank-normalized them and then used them with the GCTA software (Supplementary Table S7). The SNP heritability of episodicity was estimated at 0.129 (s.E. $=0.148, p=0.192$ ).

Power was 0.8 to detect a SNP heritability of 0.25 for AAO and 0.37 for episodicity.

\section{Discussion}

Stratifying MDD cases by AAO and recurrence has extensively been used in MDD genetic research as early-onset and recurrent forms have been repeatedly associated with higher familial aggregation and heritability of MDD (Sullivan et al. 2000). However, there is paucity of evidence regarding the familiality and heritability of
Table 4. Maximal heritability and SNP heritability estimates for age at onset ( $A A O)$ and episodicity in $M D D$

\begin{tabular}{lll}
\hline & $\begin{array}{l}\text { Maximal heritability } \\
(\text { S.E. })^{\mathrm{a}}\end{array}$ & $\begin{array}{l}\text { SNP heritability } \\
(\text { S.E. })^{\mathrm{b}}\end{array}$ \\
\hline (sqrt)AAO & $0.56(0.11)$ & $0.17(0.10)$ \\
& $0.46(0.11)^{\mathrm{c}}$ & - \\
Episodicity $^{\mathrm{d}}$ & $0.15(0.02)$ & $0.09(0.14)$ \\
& $0.33(0.10)$ & $0.13(0.15)$ \\
\hline
\end{tabular}

\footnotetext{
${ }^{a}$ Maximal heritabilities, calculated as twice the ICC estimates from the DeNt affected full-siblings sample, provide an upper limit to narrow-sense heritability.

${ }^{\mathrm{b}}$ Single nucleotide polymorphism (SNP) heritabilities in genotyped cases (merged RADIANT and GSK Munich samples) provide a lower limit to narrow-sense heritability.

${ }^{c}$ Two estimates are provided depending on whether age was included as covariate (lower line) in the model or not (upper line).

${ }^{d}$ Two estimates are provided depending on the method of calculation used (negative binomial generalized linear mixed model, upper line; linear mixed model, lower line; full details in text).
}

these MDD subphenotypes. By contrast, several other subphenotypes, such as symptom clusters or dimensions, illness chronicity, personality traits, subaffective temperament profile or suicidality, have been shown to be familial or heritable in MDD (Farmer et al. 2003; Dikeos et al. 2004; Korszun et al. 2004; Mondimore et al. 2006; McGirr et al. 2009; Aguiar Ferreira et al. 2013; Lai et al. 2013). Research into the genetic correlates of MDD subphenotypes might help elucidate the pathogenesis of MDD itself, given that it is phenotypically and genetically 
heterogeneous. Furthermore, assuming that specific subphenotypes are familial and heritable, one could further explore their pleiotropic cross-phenotype genetic correlations with other psychiatric disorders, medical co-morbidities, personality traits or environmental stressors (Lee et al. 2012; Solovieff et al. 2013).

This is the first study to systematically investigate the familiality of AAO and episodicity in MDD. The two subphenotypes were analyzed as continuous traits in mixed models, which allowed us to investigate their familial clustering as well as the strength of intrafamilial correlations (ICC). To investigate the familiality of episodicity, we fitted two alternative models; a NB GLMM for episode count and a simpler LMM for $\ln$ (episode frequency). To calculate the ICC of episodicity in the first model, we relied on a modification of a novel, recently published statistical formulation of an ICC in GLMMs for overdispersed count data (Carrasco \& Jover, 2003, 2005; Carrasco, 2010). Significant familiality of both AAO and episodicity was found in the DeNt affected full siblings sample. A moderate proportion of the variance of (sqrt)AAO (ICC $=0.23$ with age adjustment and ICC $=0.28$ without age adjustment) was attributed to family membership. Analysing episodicity, both methods produced small ICC estimates (0.07 and 0.17, respectively). However, since the number of depressive episodes is a count variable, we consider the NB GLMM method as more precise while the LMM method produces inflated estimates.

The heritability of AAO and episodicity has, similarly, rarely been studied; negligible estimates have been reported for both subphenotypes in a small female-only twin study (Kendler et al. 1992). We calculated an upper bound estimate of narrow-sense heritability ('maximal heritability') of AAO and episodicity in MDD from respective ICC estimates (Table 4). AAO seems to be under stronger additive genetic control than episodicity. Almost half of the variance of AAO and the greatest part of the variance of episodicity are, however, controlled by unique environment and stochastic events. Yet, it is highly probable that gene-environment interactions, which are difficult to disentangle from unique environmental effects (Purcell, 2002; Purcell \& Sham, 2002), also contribute. Furthermore, part of the additive genetic variance component of our subphenotypes might in fact be contributed by genetic control of environmental exposure (Kendler \& Karkowski-Shuman, 1997; Power et al. 2013).

We finally calculated the SNP heritability of the two subphenotypes in unrelated MDD subjects with the GREML procedure in GCTA software (Yang et al. 2011). This represents a lower limit to narrow-sense heritability by estimating its component which is captured by common variants (Zaitlen \& Kraft, 2012).
The SNP heritability of AAO was small but significant $(0.17, p=0.04)$. Estimates were non-significant for episodicity (0.09 and 0.13 , depending on the calculation method) (Table 4); our study lacked power to detect significant and accurate estimates of this magnitude, and much larger studies will be required (Visscher et al. 2014).

Our AAO analysis used AAO as a continuous outcome variable, but time-to-event (survival) analysis could alternatively be used, which would also take into account controls who have not manifested depression at their age at interview; Cox regression models with random effects (also known as 'shared-frailty models') have been described (Therneau \& Grambsch, 2000). Although such an analysis would be feasible for genotyped subjects after adding controls, few unaffected DeNt siblings were recruited and we, therefore, opted for the analysis of AAO as a quantitative trait in both datasets so that maximal heritability and SNP heritability estimates thence derived could be comparable.

Similarly, survival models for recurrent events (multiple-failure data) could be used to analyze episodicity (Baethge \& Schlattmann, 2004). These models allow for the effects of prior episode number, therapeutic interventions, episode duration, episodedependent covariates and unobserved heterogeneity (frailty) in recurrence-prone tendency on the risk of future recurrences (Kessing et al. 1999; Solomon et al. 2000) but could not be applied here as our data lacked information on timing and duration of each episode. Our NB model assumes that episodes are independent events while a semi-parametric survival model would withhold any assumptions about the distribution of episode count; the results of our analysis might, therefore, be subject to some bias.

Two genome-wide studies of the genetic architecture of AAO and episodicity in the RADIANT sample have been published. A GWAS of AAO, analyzed with three different methods, produced no genome-wide significant findings; a non-replicated genome-wide association with the TUSC3 gene in young males with an early AAO was recorded (Power et al. 2012). A preliminary estimate of 0.55 (S.E. $=0.27, p=0.02$ ) for the SNP heritability of (sqrt)AAO was also reported in this study. This earlier estimate, which is substantially higher than our current estimate, was based on AAO in UK cases only, and unadjusted for the effects of sex and COhort (study and center); in the present study, we adjusted sqrtAAO for these covariates, and extended the analysis to MDD cases ascertained from sites across Europe (including the UK) and one site in St Louis, USA. Similarly, a GWAS of episodicity in the RADIANT sample produced only non-replicated findings of suggestive significance; interestingly, polygenic profile analyses 
based on the PGC MDD and bipolar studies showed that, in subjects with positive family history of MDD, episodicity was predicted by both MDD and bipolar polygenes (Ferentinos et al. 2014). These preliminary studies suggest that investigations in larger collaborative samples are certainly warranted.

Bipolar disorder, unlike MDD, shows evidence of the familiality and heritability of AAO and episodicity subphenotypes. Available studies are either based on extended families ascertained through bipolar probands and including relatives with major affective disorders or on clusters of bipolar siblings. AAO is familial, with reported ICC estimates of 0.1 (Schulze et al. 2006), 0.29 (O'Mahony et al. 2002) and 0.42 (Leboyer et al. 1998), while affected siblings of early-onset (AAO£21 years) probands were 4.5 times more likely than others to have an early onset (Lin et al. 2006). AAO was estimated to have a heritability of 0.52 in 27 extended families ascertained for bipolar disorder (Visscher et al. 2001). Episode frequency was significantly correlated among bipolar probands and their affected relatives with major affective disorders $(\mathrm{ICC}=0.56)$ (Fisfalen et al. 2005), refuting a previously reported much lower estimate of 0.15 which did not survive multiple testing correction (O'Mahony et al. 2002). Other subphenotypes have been shown to be familial in bipolar disorder, including psychotic symptoms, sleep disturbances, proportion of manic to depressive episodes, polarity at illness onset, suicidality, comorbidities (panic disorder, alcohol and substance abuse), and the quality of social relations (MacKinnon et al. 1997; Potash et al. 2001; O'Mahony et al. 2002; Dikeos et al. 2004; Kassem et al. 2006; Schulze et al. 2006; Lai et al. 2013).

Our study comes with some additional limitations. First, episode count was retrospectively self-reported during the SCAN interview without validation from external sources; it may be subject to recall bias and be influenced by the patient's current mood state or personality characteristics (neuroticism, histrionic traits). Second, while maximal heritabilities of AAO and episodicity were derived from phenotypic correlations in a sample with familial MDD (DeNt siblings), SNP heritabilities were assessed in the merged RADIANT and GSK Munich sample where $54.4 \%$ of subjects had positive family history of MDD in first-degree relatives; low power did not allow us to recalculate SNP heritabilities for this specific subset. Third, ICC estimates were calculated in DeNt siblings suffering from recurrent MDD, and the SNP heritability of episodicity was assessed in 2368 genotyped cases with recurrent MDD; on the other hand, the SNP heritability of AAO was assessed in 3468 cases, of which $92 \%$ had recurrent MDD. Therefore, since heritabilities of $\mathrm{AAO}$ and episodicity might be different in familial $v$. non-familial MDD and in recurrent $v$. single episode forms, Table 4 should be interpreted with caution.

In conclusion, this study systematically investigated the familiality of AAO and episodicity in a sample of full siblings with recurrent MDD. Significant familiality of both was found; the strength of the familial effect was moderate for AAO and low for episodicity. An estimate of the upper limit to the narrow-sense heritability of the two subphenotypes was calculated from ICC values. AAO is under stronger additive genetic control than episodicity. We also estimated in unrelated MDD subjects the proportion of the variance of AAO explained by common SNPs (SNP heritability) with the GREML procedure in GCTA software. Analysis was underpowered for calculating SNP heritability of episodicity, confirming the need for larger samples. The statistical framework described here could be useful in future analyses. Assuming there is a substantial genetic basis for AAO and episodicity, one could further explore their pleiotropic genetic correlations with various other traits or conditions in order to unravel additional aspects in the pathogenesis, onset and course of MDD.

\section{Supplementary material}

For supplementary material accompanying this paper visit http://dx.doi.org/10.1017/S0033291715000215.

\section{Acknowledgements}

This study presents independent research part funded by a joint grant from the Medical Research Council, UK and GlaxoSmithKline (G0701420), and by financial support from the National Institute for Health Research (NIHR) Biomedical Research Centre for Mental Health at the South London and Maudsley NHS Foundation Trust and King's College London. The views expressed are those of the authors and not necessarily those of the NHS, the NIHR or the Department of Health. This work was also supported by the German Federal Ministry of Education and Research within the context of the German National Genome Research Network (NGFN-2 and NGFNplus). GlaxoSmithKline funded the collection of the DeNt cohort of depression cases, the genotyping of all RADIANT cases (with the MRC), and both the collection and genotyping of the GSK Munich cohort of depression cases. The GENDEP project was funded by the European Commission Framework 6 grant, EC Contract Ref.: LSHB-CT-2003-503428. Lundbeck provided nortriptyline and escitalopram for the GENDEP study. GlaxoSmithKline and the UK NIHR of the Department of Health contributed to the 
funding of the sample collection at the Institute of Psychiatry, London. A.K. is supported through NIHR/BRC funding. R.U. was supported by a grant from the European Commission (Grant Agreement no. 115008). The sponsors had no role in the design and conduct of the study, in data collection, analysis, interpretation, writing of the report, or in the decision to submit the paper for publication. Dr Aitchison holds an Alberta Centennial Addiction and Mental Health Research Chair, funded by the Government of Alberta. We are particularly grateful to Dr J. Carrasco for helpful comments on our statistical analysis.

\section{Declaration of Interest}

K. J. Aitchison, A. E. Farmer and P. McGuffin have received consultancy fees and honoraria for participating in expert panels for pharmaceutical companies including GlaxoSmithKline. M. Ising has received consultancy honoraria from MSD Merck. E. B. Binder has received grant support from PharmaNeuroboost. N. Henigsberg has participated in clinical trials sponsored by GlaxoSmithKline and Lundbeck. C. M. Lewis has received consultancy honoraria from Eli Lilly. There are no patents, products in development or marketed products to declare. All other authors declare no conflicts of interest.

\section{References}

Aguiar Ferreira A, Vasconcelos AG, Neves FS, Laks J, Correa H (2013). Affective temperaments: familiality and clinical use in mood disorders. Journal of Affective Disorders 148, 53-56.

Baethge C, Schlattmann P (2004). A survival analysis for recurrent events in psychiatric research. Bipolar Disorders 6, 115-121.

Blom G (1958). Statistical estimates and transformed beta variables. John Wiley and Sons: New York.

Bolker BM, Brooks ME, Clark CJ, Geange SW, Poulsen JR, Stevens MH, White JS (2009). Generalized linear mixed models: a practical guide for ecology and evolution. Trends in Ecology \& Evolution 24, 127-135.

Breen G, Webb BT, Butler AW, van den Oord EJ, Tozzi F, Craddock N, Gill M, Korszun A, Maier W, Middleton L, Mors O, Owen MJ, Cohen-Woods S, Perry J, Galwey NW, Upmanyu R, Craig I, Lewis CM, Ng M, Brewster S, Preisig M, Rietschel M, Jones L, Knight J, Rice J, Muglia P, Farmer AE, McGuffin P (2011). A genome-wide significant linkage for severe depression on chromosome 3: the depression network study. American Journal of Psychiatry 168, 840-847.

Carrasco JL (2010). A generalized concordance correlation coefficient based on the variance components generalized linear mixed models for overdispersed count data. Biometrics 66, 897-904.

Carrasco JL, Jover L (2003). Estimating the generalized concordance correlation coefficient through variance components. Biometrics 59, 849-858.

Carrasco JL, Jover L (2005). Concordance correlation coefficient applied to discrete data. Statistics in Medicine 24, 4021-434.
Cohen-Woods S, Gaysina D, Craddock N, Farmer A, Gray J, Gunasinghe C, Hoda F, Jones L, Knight J, Korszun A, Owen MJ, Sterne A, Craig IW, McGuffin P (2009).

Depression Case Control (DeCC) Study fails to support involvement of the muscarinic acetylcholine receptor M2 (CHRM2) gene in recurrent major depressive disorder. Human Molecular Genetics 18, 1504-1509.

Dikeos DG, Papadimitriou GN, Soldatos CR (2004). Familial aggregation of suicidal ideation in psychiatric patients: influence of gender. Neuropsychobiology 50, 216-220.

Falconer DS, Mackay TFC (1996). Introduction to Quantitative Genetics. Pearson Education Ltd: Edinburgh.

Farmer A, Breen G, Brewster S, Craddock N, Gill M, Korszun A, Maier W, Middleton L, Mors O, Owen M, Perry J, Preisig M, Rietschel M, Reich T, Jones L, Jones I, McGuffin P (2004). The Depression Network (DeNT) Study: methodology and sociodemographic characteristics of the first 470 affected sibling pairs from a large multi-site linkage genetic study. BMC Psychiatry 4, 42.

Farmer A, Mahmood A, Redman K, Harris T, Sadler S, McGuffin P (2003). A sib-pair study of the Temperament and Character Inventory scales in major depression. Archives of General Psychiatry 60, 490-496.

Ferentinos P, Rivera M, Ising M, Spain SL, Cohen-Woods S, Butler AW, Craddock N, Owen MJ, Korszun A, Jones L, Jones I, Gill M, Rice JP, Maier W, Mors O, Rietschel M, Lucae S, Binder EB, Preisig M, Tozzi F, Muglia P, Breen G, Craig IW, Farmer AE, Muller-Myhsok B, McGuffin P, Lewis CM (2014). Investigating the genetic variation underlying episodicity in major depressive disorder: suggestive evidence for a bipolar contribution. Journal of Affective Disorders 155, 81-89.

Fisfalen ME, Schulze TG, DePaulo JR Jr., DeGroot LJ, Badner JA, McMahon FJ (2005). Familial variation in episode frequency in bipolar affective disorder. American Journal of Psychiatry 162, 1266-1272.

Kassem L, Lopez V, Hedeker D, Steele J, Zandi P, McMahon FJ (2006). Familiality of polarity at illness onset in bipolar affective disorder. American Journal of Psychiatry 163, 17541759.

Kendler KS, Karkowski-Shuman L (1997). Stressful life events and genetic liability to major depression: genetic control of exposure to the environment? Psychological Medicine 27, 539-547.

Kendler KS, Neale MC, Kessler RC, Heath AC, Eaves LJ (1992). Familial influences on the clinical characteristics of major depression: a twin study. Acta Psychiatrica Scandinavica 86, 371-378.

Kessing LV, Olsen EW, Andersen PK (1999). Recurrence in affective disorder: analyses with frailty models. American Journal of Epidemiology 149, 404-411.

Kohli MA, Lucae S, Saemann PG, Schmidt MV, Demirkan A, Hek K, Czamara D, Alexander M, Salyakina D, Ripke S, Hoehn D, Specht M, Menke A, Hennings J, Heck A, Wolf C, Ising M, Schreiber S, Czisch M, Muller MB, Uhr M, Bettecken T, Becker A, Schramm J, Rietschel M, Maier W, Bradley B, Ressler KJ, Nothen MM, Cichon S, Craig IW, Breen G, Lewis CM, Hofman A, Tiemeier H, van Duijn CM, Holsboer F, Muller-Myhsok B, Binder EB 
(2011). The neuronal transporter gene SLC6A15 confers risk to major depression. Neuron 70, 252-265.

Korszun A, Moskvina V, Brewster S, Craddock N, Ferrero F, Gill M, Jones IR, Jones LA, Maier W, Mors O, Owen MJ, Preisig M, Reich T, Rietschel M, Farmer A, McGuffin P (2004). Familiality of symptom dimensions in depression. Archives of General Psychiatry 61, 468-474.

Lai YC, Huang MC, Chen HC, Lu MK, Chiu YH, Shen WW, Lu RB, Kuo PH (2013). Familiality and clinical outcomes of sleep disturbances in major depressive and bipolar disorders. Journal of Psychosomatic Research 76, 61-67.

Leboyer M, Bellivier F, McKeon P, Albus M, Borrman M, Perez-Diaz F, Mynett-Johnson L, Feingold J, Maier W (1998). Age at onset and gender resemblance in bipolar siblings. Psychiatry Research 81, 125-131.

Lee SH, Yang J, Goddard ME, Visscher PM, Wray NR (2012). Estimation of pleiotropy between complex diseases using single-nucleotide polymorphism-derived genomic relationships and restricted maximum likelihood. Bioinformatics 28, 2540-2542.

Lewis CM, Ng MY, Butler AW, Cohen-Woods S, Uher R, Pirlo K, Weale ME, Schosser A, Paredes UM, Rivera M, Craddock N, Owen MJ, Jones L, Jones I, Korszun A, Aitchison KJ, Shi J, Quinn JP, Mackenzie A, Vollenweider P, Waeber G, Heath S, Lathrop M, Muglia P, Barnes MR, Whittaker JC, Tozzi F, Holsboer F, Preisig M, Farmer AE, Breen G, Craig IW, McGuffin P (2010). Genome-wide association study of major recurrent depression in the U.K. population. American Journal of Psychiatry 167, 949-957.

Lin PI, McInnis MG, Potash JB, Willour V, MacKinnon DF, DePaulo JR, Zandi PP (2006). Clinical correlates and familial aggregation of age at onset in bipolar disorder. American Journal of Psychiatry 163, 240-246.

MacKinnon DF, McMahon FJ, Simpson SG, McInnis MG, DePaulo JR (1997). Panic disorder with familial bipolar disorder. Biological Psychiatry 42, 90-95.

McGirr A, Alda M, Seguin M, Cabot S, Lesage A, Turecki G (2009). Familial aggregation of suicide explained by cluster B traits: a three-group family study of suicide controlling for major depressive disorder. American Journal of Psychiatry 166, 1124-1134.

McGuffin P, Knight J, Breen G, Brewster S, Boyd PR, Craddock N, Gill M, Korszun A, Maier W, Middleton L, Mors O, Owen MJ, Perry J, Preisig M, Reich T, Rice J, Rietschel M, Jones L, Sham P, Farmer AE (2005). Whole genome linkage scan of recurrent depressive disorder from the depression network study. Human Molecular Genetics 14, 3337-3345.

Mondimore FM, Zandi PP, Mackinnon DF, McInnis MG, Miller EB, Crowe RP, Scheftner WA, Marta DH, Weissman MM, Levinson DF, Murphy-Ebenez KP, Depaulo JR Jr., Potash JB (2006). Familial aggregation of illness chronicity in recurrent, early-onset major depression pedigrees. American Journal of Psychiatry 163, 1554-1560.

Muglia P, Tozzi F, Galwey NW, Francks C, Upmanyu R, Kong XQ, Antoniades A, Domenici E, Perry J, Rothen S, Vandeleur CL, Mooser V, Waeber G, Vollenweider P, Preisig M, Lucae S, Muller-Myhsok B, Holsboer F,
Middleton LT, Roses AD (2010). Genome-wide association study of recurrent major depressive disorder in two European case-control cohorts. Molecular Psychiatry 15, 589-601.

O'Mahony E, Corvin A, O'Connell R, Comerford C, Larsen B, Jones R, McCandless F, Kirov G, Cardno AG, Craddock N, Gill M (2002). Sibling pairs with affective disorders: resemblance of demographic and clinical features. Psychological Medicine 32, 55-61.

PGC (2013). A mega-analysis of genome-wide association studies for major depressive disorder. Molecular Psychiatry 18, 497-511.

Potash JB, Willour VL, Chiu YF, Simpson SG, MacKinnon DF, Pearlson GD, DePaulo JR Jr., McInnis MG (2001). The familial aggregation of psychotic symptoms in bipolar disorder pedigrees. American Journal of Psychiatry 158, 1258-1264.

Power RA, Keers R, Ng MY, Butler AW, Uher R, Cohen-Woods S, Ising M, Craddock N, Owen MJ, Korszun A, Jones L, Jones I, Gill M, Rice JP, Hauser J, Henigsberg N, Maier W, Zobel A, Mors O, Placentino AS, Rietschel M, Souery D, Kozel D, Preisig M, Lucae S, Binder EB, Aitchison KJ, Tozzi F, Muglia P, Breen G, Craig IW, Farmer AE, Muller-Myhsok B, McGuffin P, Lewis CM (2012). Dissecting the genetic heterogeneity of depression through age at onset. American Journal of Medical Genetics Part B Neuropsychiatric Genetics 159B, 859-868.

Power RA, Wingenbach T, Cohen-Woods S, Uher R, Ng MY, Butler AW, Ising M, Craddock N, Owen MJ, Korszun A, Jones L, Jones I, Gill M, Rice JP, Maier W, Zobel A, Mors O, Placentino A, Rietschel M, Lucae S, Holsboer F, Binder EB, Keers R, Tozzi F, Muglia P, Breen G, Craig IW, Muller-Myhsok B, Kennedy JL, Strauss J, Vincent JB, Lewis CM, Farmer AE, McGuffin P (2013). Estimating the heritability of reporting stressful life events captured by common genetic variants. Psychological Medicine 43, 1965-1971.

Purcell S (2002). Variance components models for gene-environment interaction in twin analysis. Twin Research 5, 554-571.

Purcell S, Neale B, Todd-Brown K, Thomas L, Ferreira MA, Bender D, Maller J, Sklar P, de Bakker PI, Daly MJ, Sham PC (2007). PLINK: a tool set for whole-genome association and population-based linkage analyses. American Journal of Human Genetics 81, 559-575.

Purcell S, Sham P (2002). Variance components models for gene-environment interaction in quantitative trait locus linkage analysis. Twin Research 5, 572-576.

Rietschel M, Mattheisen M, Frank J, Treutlein J, Degenhardt F, Breuer R, Steffens M, Mier D, Esslinger C, Walter H, Kirsch P, Erk S, Schnell K, Herms S, Wichmann HE, Schreiber S, Jockel KH, Strohmaier J, Roeske D, Haenisch B, Gross M, Hoefels S, Lucae S, Binder EB, Wienker TF, Schulze TG, Schmal C, Zimmer A, Juraeva D, Brors B, Bettecken T, Meyer-Lindenberg A, Muller-Myhsok B, Maier W, Nothen MM, Cichon S (2010). Genome-wide association-, replication-, and neuroimaging study implicates HOMER1 in the etiology of major depression. Biological Psychiatry 68, 578-585.

Schulze TG, Hedeker D, Zandi P, Rietschel M, McMahon FJ (2006). What is familial about familial bipolar disorder? Resemblance among relatives across a broad spectrum of 
phenotypic characteristics. Archives of General Psychiatry 63, 1368-1376.

Shi J, Potash JB, Knowles JA, Weissman MM, Coryell W, Scheftner WA, Lawson WB, DePaulo JR Jr., Gejman PV, Sanders AR, Johnson JK, Adams P, Chaudhury S, Jancic D, Evgrafov O, Zvinyatskovskiy A, Ertman N, Gladis M, Neimanas K, Goodell M, Hale N, Ney N, Verma R, Mirel D, Holmans P, Levinson DF (2011). Genome-wide association study of recurrent early-onset major depressive disorder. Molecular Psychiatry 16, 193-201.

Shyn SI, Shi J, Kraft JB, Potash JB, Knowles JA, Weissman MM, Garriock HA, Yokoyama JS, McGrath PJ, Peters EJ, Scheftner WA, Coryell W, Lawson WB, Jancic D, Gejman PV, Sanders AR, Holmans P, Slager SL, Levinson DF, Hamilton SP (2011). Novel loci for major depression identified by genome-wide association study of Sequenced Treatment Alternatives to Relieve Depression and meta-analysis of three studies. Molecular Psychiatry 16, 202-215.

Solomon DA, Keller MB, Leon AC, Mueller TI, Lavori PW, Shea MT, Coryell W, Warshaw M, Turvey C, Maser JD, Endicott J (2000). Multiple recurrences of major depressive disorder. American Journal of Psychiatry 157, 229-233.

Solovieff N, Cotsapas C, Lee PH, Purcell SM, Smoller JW (2013). Pleiotropy in complex traits: challenges and strategies. Nature Review Genetics 14, 483-495.

StataCorp (2013). Stata Statistical Software: Release 13. StataCorp LP: College Station, TX.

Sullivan PF, de Geus EJ, Willemsen G, James MR, Smit JH, Zandbelt T, Arolt V, Baune BT, Blackwood D, Cichon S, Coventry WL, Domschke K, Farmer A, Fava M, Gordon SD, He Q, Heath AC, Heutink P, Holsboer F, Hoogendijk WJ, Hottenga JJ, Hu Y, Kohli M, Lin D, Lucae S, Macintyre DJ, Maier W, McGhee KA, McGuffin P, Montgomery GW, Muir WJ, Nolen WA, Nothen MM, Perlis RH, Pirlo K, Posthuma D, Rietschel M, Rizzu P, Schosser A, Smit AB, Smoller JW, Tzeng JY, van Dyck R, Verhage M, Zitman FG, Martin NG, Wray NR, Boomsma DI, Penninx BW (2009). Genome-wide association for major depressive disorder: a possible role for the presynaptic protein piccolo. Molecular Psychiatry 14, 359-375.

Sullivan PF, Neale MC, Kendler KS (2000). Genetic epidemiology of major depression: review and meta-analysis. American Journal of Psychiatry 157, 1552-1562.

Tenesa A, Haley CS (2013). The heritability of human disease: estimation, uses and abuses. Nature Review Genetics 14, 139-149.

Therneau TM, Grambsch PM (2000). Modeling Survival Data: Extending the Cox Model. Springer: New York.
Tozzi F, Prokopenko I, Perry JD, Kennedy JL, McCarthy AD, Holsboer F, Berrettini W, Middleton LT, Chilcoat HD, Muglia P (2008). Family history of depression is associated with younger age of onset in patients with recurrent depression. Psychological Medicine 38, 641-649.

Uher R, Maier W, Hauser J, Marusic A, Schmael C, Mors O, Henigsberg N, Souery D, Placentino A, Rietschel M, Zobel A, Dmitrzak-Weglarz M, Petrovic A, Jorgensen L, Kalember P, Giovannini C, Barreto M, Elkin A, Landau S, Farmer A, Aitchison KJ, McGuffin P (2009). Differential efficacy of escitalopram and nortriptyline on dimensional measures of depression. British Journal of Psychiatry 194, 252-259.

Visscher PM, Hemani G, Vinkhuyzen AA, Chen GB, Lee SH, Wray NR, Goddard ME, Yang J (2014). Statistical power to detect genetic (co)variance of complex traits using SNP data in unrelated samples. PLoS Genetics 10, e1004269.

Visscher PM, Hill WG, Wray NR (2008). Heritability in the genomics era - concepts and misconceptions. Nature Review Genetics 9, 255-266.

Visscher PM, Yazdi MH, Jackson AD, Schalling M, Lindblad K, Yuan QP, Porteous D, Muir WJ, Blackwood DH (2001). Genetic survival analysis of age-at-onset of bipolar disorder: evidence for anticipation or cohort effect in families. Psychiatric Genetics 11, 129-137.

Wing JK, Babor T, Brugha T, Burke J, Cooper JE, Giel R, Jablenski A, Regier D, Sartorius N (1990). SCAN. Schedules for Clinical Assessment in Neuropsychiatry. Archives of General Psychiatry 47, 589-593.

Wray NR, Pergadia ML, Blackwood DH, Penninx BW, Gordon SD, Nyholt DR, Ripke S, MacIntyre DJ, McGhee KA, Maclean AW, Smit JH, Hottenga JJ, Willemsen G, Middeldorp CM, de Geus EJ, Lewis CM, McGuffin P, Hickie IB, van den Oord EJ, Liu JZ, MacGregor S, McEvoy BP, Byrne EM, Medland SE, Statham DJ, Henders AK, Heath AC, Montgomery GW, Martin NG, Boomsma DI, Madden PA, Sullivan PF (2012).

Genome-wide association study of major depressive disorder: new results, meta-analysis, and lessons learned. Molecular Psychiatry 17, 36-48.

Wynants L, Timmerman D, Bourne T, Van Huffel S, Van Calster B (2013). Screening for data clustering in multicenter studies: the residual intraclass correlation. BMC Medical Research Methodology 13, 128.

Yang J, Lee SH, Goddard ME, Visscher PM (2011). GCTA: a tool for genome-wide complex trait analysis. American Journal of Human Genetics 88, 76-82.

Zaitlen N, Kraft P (2012). Heritability in the genome-wide association era. Human Genetics 131, 1655-1664. 